\title{
A NEW DIRECTION FOR SCIENCE AND VALUES
}

\author{
DAN HICKS
}

\author{
Forthcoming in Synthese
}

\begin{abstract}
The controversy over the old ideal of "value-free science" has cooled significantly over the past decade. Many philosophers of science now agree that even ethical and political values may play a substantial role in all aspects of scientific inquiry. Consequently, in the last few years, work in science and values has become more specific: Which values may influence science, and in which ways? Or, how do we distinguish illegitimate from illegitimate kinds of influence? In this paper, I argue that this problem requires philosophers of science to take a new direction. I present two case studies in the influence of values on scientific inquiry: feminist values in archaeology and commercial values in pharmaceutical research. I offer a preliminary assessment of these cases, that the influence of values was legitimate in the feminist case, but not in the pharmaceutical case. I then turn to three major approaches to distinguish legitimate from illegitimate influences of values, including the distinction between epistemic and non-epistemic values and Heather Douglas' distinction between direct and indirect roles for values. I argue that none of these three approaches gives an adequate analysis of the two cases. In the concluding section, I briefly sketch my own approach, which draws more heavily on ethics than the others, and is more promising as a solution to the current problem. This is the new direction in which I think science and values should move.
\end{abstract}

Date: March 13, 2014.

Thanks to Kevin Elliott, Heather Douglas, Charles Pence, Robert Audi, Amelia Hicks, Kenny Boyce, Aaron Segal, Rachael Brown, Kerry McKenzie, and Keizo Matsurbara for comments on earlier versions. 


\section{Introduction}

The controversy over the ideal of "value-free science," while not completely settled (for a recent salvo, see Betz 2013), has cooled significantly over the past decade. Many philosophers of science, and perhaps most specialists in the role of values in science, now agree that even ethical and political values may play a substantial role in all aspects of scientific inquiry, including the evaluation and acceptance of hypotheses. In addition, almost no philosophers have ever been attracted to the "anything-goes" relativism that was the primary rhetorical foil to the value-free ideal during the so-called Science Wars. Philosophers generally accept some constraints on the kinds of values that may influence science, or the ways in which they may have an influence. Consequently, in the last few years, work in science and values has become more specific: Granted that at least some values may influence science, in at least some ways, which values may do so, and in which ways? Or, to put it slightly differently, how do we distinguish cases in which the influence of values is legitimate from cases in which it is illegitimate?

In this paper, I argue that addressing these questions requires philosophy of science to take a new direction. After replacing talk of "the value-free ideal" with more precise language, in $\S 2$ I present two cases in which ethical and political values had a significant influence on science. One case deals with the influence of feminist values in archaeology; the other case deals with the influence of commercial values in pharmaceutical research. I sketch an analysis of these cases, which indicates that the influence of values was legitimate in the feminist case, but illegitimate in the pharmaceutical. This preliminary judgment is of course incompatible with both the value-free ideal and an "anything-goes" view. In recent work, philosophers have tried to analyze these kinds of cases using tools developed in the earlier debates over the value-free ideal. In $\$ \S 3-5$, I review three such sets of tools and three such analyses. In each case, I argue that the analysis is inadequate. Roughly, either the analysis is incompatible with the preliminary judgment about the two cases (e.g., it concludes that the influence of feminist values was illegitimate), or it relies on a problematic assumption about the value of the pursuit of truth. ${ }^{1}$ In $\S 6$ I

\footnotetext{
1. I am not interested in the scientific realism vs. antirealism debate here, or the nature of truth as such. Rather, my interest is in our attitudes towards truth, the ways in which we pursue it, and how these pursuits relate to other activities. That is, I'm interested in these relational properties of truth rather than
} 
develop my own approach, which draws heavily on resources in ethics and accounts of practical reason. This is the "new direction" of the title: philosophers of science should undertake a deeper engagement with ethics, which will enable us to bring together both epistemological and ethical considerations.

To this point, I have spoken loosely of "the value-free ideal" and "the influence of values." In the remainder of this introduction, I lay out more precise language and review some major developments in the science and values literature over the past decade. (The presentation below is heavily indebted to Hugh Lacey's discussion of these issues.)

It is common to divide the activity of scientific inquiry into several "contexts," "moments," "steps," or "phases" (for examples from the science and values literature, see Anderson 2004, 6-7; Lacey 2005a; 2005b, §3.4; Douglas 2009, 88ff; K. Elliott 2011, chapter 3; Kitcher 2011, 31ff, 2013; Brown 2013c, 2). While the details of these taxonomies vary widely, all are compatible with a coarse division along the following lines:

(1) A pre-epistemic phase, during which research programs are chosen, hypotheses are formulated, and experiments are designed and conducted. ${ }^{2}$

its intrinsic properties. Throughout this paper, I generally use "truth" as a generic term for the epistemic aim or aims of scientific inquiry, especially when and insofar as these are "purely epistemic," that is, independent of or contrasting with the aims of "applied science" and engineering.

Truth in the sense usually connected to scientific realism is one such aim, but other such aims include Bas van Fraassen's empirical adequacy (1980) and Michael Friedman's communicative rationality (2001). Daniel Steel seems to use "truth" in something like the narrower, scientific realist sense, and so when I discuss his views in $\S 4$ I follow his lead; however, little or nothing in the argument of that section turns on the nature of truth or scientific realism vs. antirealism. Truth in the Deweyan sense of "effectively resolves the current problematic situation" is not covered by "truth" as I use it there, since this sense of "truth" ties it closely to the pragmatic, not "purely epistemic" aims of "applied science" and engineering (Brown 2012).

Throughout this paper, I speak of truth "as a value," and discuss how this value relates to ethical and political values. Again, my interest is in our attitude towards truth - how we value it - and how this relates to other things that we value. Speaking of truth in this way does not imply that it is "merely" a value, that truth as such is entirely subjective, and so on. Indeed, presumably we value truth (in any of the senses given in the last paragraph) because it is not entirely subjective. Talking about truth as a value is entirely consistent with taking truth or some necessary condition for truth to be a necessary condition for accepting a theory. For instance, it is entirely consistent with taking internal consistency to be necessary for accepting a theory on the grounds that internal consistency is necessary for truth. Indeed, in this case we are attaching a great deal of value to truth; this is what I have in mind by the lexical priority of truth, discussed below. This way of using "value" differs somewhat from Douglas (2009, 94-5), though not so much from Douglas (2013). See also note 12. I thank several readers, including an anonymous reviewer at Synthese, for encouraging me to clarify my use of "truth" and "truth as a value."

2. I use such terms as "hypotheses," "theories," "models," and "accounts" roughly interchangeably throughout this paper, and take no position in the debates over the syntactical and semantic views or the status and role of models. 
(2) An epistemic phase, during which hypotheses are evaluated in terms of their relationship to empirical evidence, among other things, and accepted or rejected.

(3) A post-epistemic phase, during which accepted hypotheses are utilized in other research (whether to produce more knowledge or new technology or both); this phase also includes the impacts of the accepted hypotheses on the broader society.

The distinction between the pre-epistemic and epistemic phases seems to be descended from the classical distinction between the contexts of discovery and justification, without the problematic assumption that the subject of philosophy of science is coextensive with the context of justification; Kitcher, for one, uses the "context of" locution. Accepting and rejecting a hypothesis, in the epistemic phase, is often taken to be a strong and "purely epistemic" attitude, one that does not (or should not) depend in any way on the anticipated applications of the hypothesis (in the post-epistemic phase). Compare Hugh Lacey's distinction between acceptance and endorsement: acceptance belongs to the epistemic phase, but endorsement belongs to the post-epistemic phase (2005a, 980, 986-7). The post-epistemic phase includes not only what we might call the direct impacts of the accepted hypotheses (for example, their use in some piece of technology) but also their indirect impacts (for example, the social impacts of the use of this technology) and cultural impacts (for example, the hypotheses might reinforce stereotypes about certain social groups or challenge widely-accepted religious beliefs).

Note that I work with this taxonomy in this paper because the approaches that I discuss in $\S \S 3-5$ generally assume it, but I do not accept it myself. As the terminology suggests, these phases are usually construed linearly or progressively, with well-defined boundaries between them. But often this is an oversimplification, and indeed in $§ 5 \mathrm{I}$ will argue that in some important cases the phases cannot be sharply distinguished: one action, described one way, is epistemic; but described another way, is pre-epistemic. In a classic paper, Kathleen Okruhlik argued that the evaluation of hypotheses, the epistemic phase, is often deeply influenced by both the way in which the hypotheses were generated in the pre-epistemic phase and the expected ways in which it will be utilized in the post-epistemic phase (1994). In recent work, Matthew Brown (2011, 2012) and Kevin Elliott (2012) have emphasized that the actual relationship among these phases 
is highly nonlinear, and Daniel McKaughan has pointed out the importance to scientific practice of attitudes other than acceptance and rejection (McKaughan 2007; Elliott and McKaughan 2009).

At the turn of the twenty-first century, the philosophical debate had come to focus on the epistemic phase and what is often (somewhat imprecisely) called "the ideal of value-free science." As I define the positions in the debate at that point in time, isolationism is the view that ethical and political values may not legitimately influence the standards for acceptance and rejection in this phase. Note that this is a vague evaluative claim: that values shouldn't have this influence, or that it's bad, wrong, or vicious if they do. "Influence" is also vague; there are many ways in which values might influence the epistemic phase. Roughly, isolationism can accept that ethical and political values make a difference to whether the scientific community uses these standards; as Lacey puts it, "[t]he social process has been shaped and institutionally nurtured so that it is conducive to producing soundly accepted theories" (Lacey 2005a, 981-2). Isolationism cannot accept ethical and political values making a difference to the content of these standards; the standards for acceptance and rejection should "not [be] grounded in the social or moral value of a theory, its potential to be applied to further human flourishing, a conception of the good society, or privileged economic interests" (Lacey 2005a, 980; compare Lacey 1999, 67ff, 224-5; Kindcaid, Dupré, and Wylie 2007, 13ff; Douglas 2009, 45, 180 n8; Betz 2013, 1). ${ }^{3}$

By contrast with isolationism, transactionism is the view that some ethical and political values may legitimately influence the epistemic phase of scientific inquiry - that is, they may legitimately make a difference to the content of the standards of acceptance and rejection. Note that this is the simple negation of isolationism, and strictly implies only that some values may have a legitimate influence, and perhaps only in some ways. ${ }^{4}$ Much of the philosophical debate between isolationism and transactionism has focused

3. I thank an anonymous reviewer at Synthese for pushing me to present the terminology in this section more precisely.

4. Since isolationism and transactionism are defined in terms of specifically "ethical and political" values, for the sake of presentation I often simply abbreviate this as "values." In $\S 4$, where I focus on the distinction between epistemic and non-epistemic values, I am more careful about this. 
on underdetermination arguments, and so many philosophers who are not specialists in science and values are most familiar with this part of the literature.

It is not clear to what extent anyone ever endorsed an "anything-goes" version of transactionism, that is, a view that any influence of values on hypothesis-acceptance, in any way, is legitimate. Sociologists and historians who explicitly advocated "relativism" and "symmetry" often clearly adopted these as methodological commitments for descriptive rather than normative or evaluative projects (see, for example Barnes and Bloor 1982, 23). On the other hand, they also often argued explicitly for much stronger normative (or perhaps meta-normative) claims: "[f]or the relativist there is no sense attached to the idea that some standards or beliefs are really rational as distinct from merely locally accepted as such” (27). Rorty's ironism (1991) and Feyerabend's methodological anarchism (1993) superficially support "anything-goes" views, but arguably both presuppose liberal assumptions (in the political philosophy sense) about autonomy and "unencumbered selves" (Sandel 1998; MacIntyre 2006; Biddle 2009). And the strong political commitments of feminism have always given the views of feminist scientists and philosophers robust normative content (Okruhlik 2004; Wylie and Nelson 2007). In any case, I am not aware of any contemporary philosopher of science who defends an "anything-goes" view.

In the first few years of the twenty-first century, a combination of the mainstreaming of feminist philosophy of science in North America - exemplified by Helen Longino's move to Stanford University - and Heather Douglas' recovery and extension of the inductive risk argument (Douglas 2000, 2009) - developed by William James (Magnus 2013) and, later, Carl Hempel and Richard Rudner - precipitated a rapid move away from isolationism, even by philosophers who had previously been among its staunch defenders (compare Kitcher 2001, ch. 3, with Kitcher 2011, §4; Hugh Lacey remains an important advocate of isolationism; see the discussion of impartiality in Lacey and Mariconda 2012). Consequently, specialists in science and values have generally shifted their attention from general arguments over isolationism and transactionism as such and to the specific problem of sorting out the legitimate and illegitimate ways in which values could influence science, especially in the epistemic phase. 
In §2, I make this more specific problem more concrete by introducing two case studies, one in which the influence of values on the epistemic phase was legitimate and one in which it was illegitimate. Then in §§3-5 I examine three major sets of conceptual tools developed in part to address this problem. ${ }^{5}$ I show how they can be used to analyze the two cases, but argue that their analyses are inadequate. Finally, in $\S 6$, I present my own approach.

\section{Two cases of science and values}

2.1. Feminism. Consider first the feminist case: the influence of feminism on such sciences as embryology, archaeology, and anthropology since the 1970s. The literature on the influence of feminism on science is vast, and "feminism" itself is understood in different ways by different writers. I will focus here on the work of self-identified feminist scientists in archaeology, as analyzed by historian Londa Schiebinger and philosopher Alison Wylie.

Wylie points out that, while feminist critiques in archaeology date back only to 1984 and "a number of those currently active in the area disavow any explicitly feminist commitments" (Wylie 2001, 23-4), there is "widespread interest in the archaeology of gender" and "much of the research done under the rubric of the archaeology of gender embodies at least a minimal commitment .... to take women and gender seriously that has resulted in contributions to archaeology that are changing its practice, its research agenda, and its understanding of the cultural past" $(25,29)$. That is, while relatively few archaeologists identify themselves as feminists, archaeology has been influenced in significant ways by feminism and feminist critique.

A significant example for Wylie is Patty Jo Watson and M.C. Kennedy's criticisms in the 1980s and 1990s of then-dominant accounts of the development of agriculture. On these accounts, women were responsible for gathering plants prior to the development of agriculture and cultivating domesticated varieties after the development of agriculture,

5. To be clear, I don't think that these three sets of tools are mutually exclusive. While the second and third - the distinction between epistemic and non-epistemic values and the distinction between direct and indirect roles for values, respectively - seem to be taken as rivals by their proponents, both involve the first, which is an assumption that Matthew Brown calls the lexical priority of evidence and which I generalize as the lexical priority of truth. 
but men were taken to be responsible for domestication and the development of agriculture itself. Watson and Kennedy pointed out a number of problematic androcentric assumptions and incoherences in these accounts, including (a) the assumption that the shamans (or the agents in other models) were men; and, correspondingly, that foragers and food preparers were women, (b) that "dabbling for ritual purposes would be more likely to produce the knowledge ... necessary for horticulture" than the activities of foragers and food preparers, and (c) that the explanation "remove[s] women from the one realm that is traditionally granted them, as soon as innovation or invention enters the picture," and so is ad hoc (Wylie 2002, 193).

In her analysis, Schiebinger emphasizes the mutually-supporting relationships between the gender structure of archaeology, standards of evidence and background assumptions, and rival hypotheses of human origins. Women in archaeology are channeled away from positions that "require active, exploratory, out-of-doors, dominant, managerial, and risk-taking work" and, when they work on stone tools, "typically study" not arrowheads and other weapons but "flake stone tools and other informal instruments found on house floors, at base camps, and in village sites" (Schiebinger 1999, 141, 142). But "men in the field have defined as interesting only a small range of tools, [weapons] ...that are celebrated as exemplifying Paleolithic life and are typically interpreted as male innovations" (141). Then, this evidence is taken to support the "man-the-hunter" hypothesis of human origins, according to which the hunting activities of men drove major developments in human biological and cultural evolution. In other words, the stone tools studied and assumed to be constructed and used by men are regarded as the most important kind of evidence about Paleolithic human societies and "human origins," and used to support androcentric hypotheses; while evidence that might challenge these androcentric hypotheses - such as stone tools assumed to be constructed and used by women - are regarded as less important and studied primarily by women.

As I have argued more extensively elsewhere, the critical work of these feminist archaeologists is both deeply feminist and deeply epistemological (Hicks 2012, §5.2). On the one hand, they directly challenge androcentrism and misogyny (roughly, male dominance) in several aspects of archaeological practice, including androcentric standards 
of evidence and explanatory frameworks and gendered hierarchies in the division of labor and specializations within archaeology. On the other hand, the standards and frameworks are epistemological criteria, that is, they are they standards used to evaluate hypotheses and proposed explanations for acceptance or rejection. Thus, when feminist archaeologists challenge these standards and frameworks, they are challenging the epistemological criteria of mainstream archaeology. And, to the extent that they developed new and alternative standards and frameworks, they developed a new epistemology for archaeology. In short, not only did feminist archaeologists reject mainstream archaeological accounts based, in part, on their feminist values; but also they challenged the content of androcentric epistemological standards. Their challenges thus took place squarely within the epistemic phase of inquiry.

2.2. Commercial Values. Consider next the pharmaceutical case: the influence of commercial values on research publication and disclosures by the pharmaceutical industry. Philip Mirowski and Robert Van Horn observe that, between the early 1980s and the late $1990 \mathrm{~s}$, the structure of pharmaceutical research changed dramatically (Mirowski and Van Horn 2005). Mirowski and Van Horn focus on the outsourcing of the research process - in other words, the actual pharmaceutical development - to contract research organizations or CROs, independent for-profit research firms contracted by pharmaceutical manufacturers to work on particular clinical research projects (see also Ledford 2013). I focus here on the new communication technologies and new institutions of command and control; specifically, I'm interested in the epistemic effects of the rise of medical communications firms or MCFs, independent for-profit companies contracted by pharmaceutical manufactures to prepare research reports and papers for publication.

Over the past decade, $\mathrm{MCF}$ s have received significant attention for their role in several pharmaceutical ghostwriting controversies. For example, Carl Elliott reports that, in a review of articles published on the antidepressant Zoloft between 1998 and 2000, "the ghostwritten and agency-prepared articles outnumbered the articles written in the traditional way. Forty-one 'traditionally authored articles on Zoloft had been published, while fifty-five articles had come from [MCF] Current Medical Directions" (C. Elliott 2004, 19). In a pair of papers, Jureidini, McHenry, and Mansfield (2008; 2008) closely 
examined the way in which GlaxoSmithKlein manipulated the interpretation of research data in a peer-reviewed publication on its antidepressant Paxil. And Berenson (2005), Biddle (2007), and Ross et al. (2008), discuss ghostwriting in another major pharmaceutical scandal, rofecoxib (Vioxx), a painkiller produced by Merck and withdrawn from the market in 2004 based on evidence that it caused heart attacks. Both the Paxil and Vioxx cases involved the MCF Scientific Therapeutics Information, and will be discussed in more detail below. And in 2010, Nature reported that "between 1997 and 2003, [MCF] DesignWrite oversaw the publication of dozens of peer-reviewed articles, conference abstracts and posters on HRT [Hormone Replacement Therapy], receiving up to US $\$ 25,000$ per project [from the manufacturer]" (Callaway 2010; for a detailed discussion of this case, see Fugh-Berman 2010).

Sergio Sismondo observes that "Visible experts are needed [by MCFs] for their authority and independence, not for the contents of their expertise. In the commercialized science I describe here, published research is valued for its marketing potential" (Sismondo 2009a, 193). Despite this, he offers two reasons for a sanguine assessment of the effects of MCFs. First, "the planners are keenly attentive to scientific norms, because it is only by meeting those norms that they can distinguish themselves from marketers, and in so doing achieve their marketing goals" (193). In other words, writers at MCFs must produce work of high epistemological quality in order to distinguish their contributions from those of marketers. Second, because of "STS's longstanding commitment to symmetry" and "canonical studies that have shown how science is choice laden," research done by CROs, written by MCFs, and funded from beginning to end by the pharmaceutical industry is "not different from other medical research, analysis, and writing"; "Pharmaceutical company research, analysis, and writing results in knowledge" (193). In other words, scientific research is always pervasively influenced by values, so there is nothing wrong with commercial values as such influencing pharmaceutical research. (To be clear, in a followup to a response by McHenry (2009), Sismondo clarifies that he is in fact deeply concerned about conflicts of interest and the power that the pharmaceutical industry exercises through CROs and MCFs (2009b).) 
Rather than giving a lengthy theoretical response to these arguments, I'll present two particular cases in which industry manipulation of peer-reviewed publications had serious epistemic effects.

The first case comes from McHenry's detailed work on an article published in the Journal of the American Academy of Child and Adolescent Psychiatry that reported the results of a clinical trial of paroxetine (Paxil), an antidepressant manufactured by SmithKline Beecham (now GlaxoSmithKline). McHenry carried out this analysis with Jon Jureidini and Peter Mansfield (Jureidini, McHenry, and Mansfield 2008; McHenry and Jureidini 2008). In brief, a professional writer at the MCF Scientific Therapeutics Information was responsible for interpreting the results of the clinical trial and preparing the drafts of the article (Jureidini, McHenry, and Mansfield 2008, 154). McHenry and Jureidini argue that the writer's interpretation was directed by SmithKline Beecham and that the nominal authors - academic scientists - did not make make substantial contributions to the article (156-8). While the results of the trial did not show that the drug was effective, the results were presented in misleading and distorted ways that suggested it was (156). Furthermore, as of August 2013, the article has been cited over 500 times, and continues to be cited as positive evidence for the efficacy and safety of Paxil and related antidepressants (Sung et al. 2013; Julious 2013; Jureidini, McHenry, and Mansfield 2008, 160, 163). (For a similar analysis of another Paxil publication, again involving Scientific Therapeutics Information, see Wadman 2011; Amsterdam and McHenry 2012.)

Ross et al. confine their attention to identifying the extent and structure of ghostwriting and guest authorship in articles on Vioxx; they do not consider the epistemic effects of ghostwriting. Berenson demonstrates these epistemic effects for one particular article, which published Vioxx clinical trial data in the Annals of Medicine. According to Jeffrey Lisse, the nominal lead author of the article, "Merck designed the trial, paid for the trial, ran the trial" (quoted in Berenson 2005; Biddle 2007, 29). As Berenson reports, during the trial, "eight people taking Vioxx suffered heart attacks or sudden cardiac death, compared with just one taking naproxen," yet the article "reported that [only] five patients taking Vioxx had suffered heart attacks during the trial, compared with one taking naproxen” (Berenson 2005, my emphasis). Emails reprinted with Berenson's report 
document an exchange between Merck executives, debating whether to classify the cause of death in one of the unreported cases as a heart attack or unknown. Apparently neither Lisse nor a committee of independent academics were informed about the unreported cases. In short, ghostwriting enabled Merck executives to suppress unfavorable evidence and thereby misrepresent a negative study as a neutral one. (Psaty and Kronmal (2008) document another instance in which data about the risks of Vioxx were misrepresented or suppressed by Merck, but do not connect it to an instance of ghostwriting.)

It seems clear that commercial values - profit-seeking - had a significant influence on the evaluation and acceptance of hypotheses concerning the efficacy and safety of Paxil and Vioxx. However, the complex organization of the trial, writing, and publication process makes it quite difficult to identify the particular ways in which these values influenced these evaluations, and which individuals might be held responsible for any illegitimate influences. Nevertheless, we can observe their epistemic consequences: the publication of false and misleading evidence, and the acceptance of hypotheses concerning the efficacy and safety of Paxil and Vioxx by regulators, clinicians, and (indirectly) patients who took these drugs. These, in turn, had consequences - probably some beneficial, certainly some harmful - for the health and well-being of the patients.

2.3. Legitimate or illegitimate? We have before us two cases in which ethical and political values influenced the epistemic phase of scientific inquiry. Are these influences legitimate?

According to the isolationist, of course, in both cases the answer is no: any influence of ethical or political values on the epistemic phase is illegitimate, and hence the influences in these cases are illegitimate. Another simple answer, from an "anything-goes" relativist, would be yes: any influence of ethical or political values on the epistemic phase is legitimate, including in these particular cases.

Neither of these simple answers is acceptable. Transactionists have given compelling conceptual and empirical arguments against isolationism, often using examples such as the feminist case. At the same time, isolationists have raised compelling worries about 
the unrestrained politicization or commercialization of scientific inquiry - worries of the same kind as seen in the pharmaceutical case. ${ }^{6}$

We need a more sophisticated analysis of the two cases. Such an analysis might start by noting that, in the feminist case, the values in question seemed to promote knowledge production. The influence of feminist values led to more empirically adequate and externally consistent theories, and a better explanatory framework. By contrast, in the pharmaceutical case, the influence of commercial values seemed to frustrate knowledge production. Regardless of the particular mechanism, they led to distortions, misrepresentations, and failures to adequately investigate relevant hypotheses. This more sophisticated answer might also point to the downstream effects of the influence of these values in the broader society: the influence of feminism may have helped undermine androcentrism and patriarchy, while the influence of commercial values led to unnecessary deaths.

This sketch suggests that the influence of values in the feminist case was legitimate, and the influence of values in the pharmaceutical case was illegitimate. However, it is just a sketch. Over the next three sections, I will attempt to use tools developed in the science and values literature to develop this sketch further. Two problems will appear several times in this discussion. First, the analysis is often highly ambiguous or indeterminate, especially in the pharmaceutical case. Whether the cases turn out to be legitimate or not depend on things like what terms we use to describe the actions of the scientists involved. Second, even when the analysis matches the preliminary assessment given in the last paragraph, it relies on a problematic assumption that truth, as a good or value, enjoys absolute priority over other goods or values. ${ }^{7}$ While this assumption may be widely shared among scientists and academics, it is not so widely shared by, for instance, representatives of the pharmaceutical industry. In light of these two problems, I conclude that none of these tools are not adequate to the task at hand. In $\S 6$, I briefly introduce my own set of tools and argue that they are more adequate to this task.

\footnotetext{
6. I do not have the space here to present two other analyses. One develops Robert Merton's ethos of science; for examples see Henk van den Belt (2010) and Hans Radder (2010a). Another points to the role of deceit in the pharmaceutical case.

7. On my use of "truth as a value," see note 1 .
} 


\section{Lexical priority of evidence}

One way of trying to give an account of the differences between the two cases appeals to an assumption that Matthew Brown calls the lexical priority of evidence to values (2013c, 2013b; see also Anderson 2004). This assumption can be traced back to responses to worries about relativism and wishful thinking. Isolationists often worry that transactionism leads to "anything-goes" relativism or problems of wishful thinking. To assuage these worries, transactionists often state explicitly that, on their view, ethical and political values have a legitimate role to play only after evidence had done as much work as it could. As Brown puts it, assuming an absolute or lexical priority of evidence to values "guarantees that even in value-laden science, values do not compete with evidence when the two conflict" (Brown 2013c, 2, 7). Contrapositively and in my terminology, when values do override considerations of evidence, the influence of values on the epistemic phase of inquiry is illegitimate.

The lexical priority of evidence gives us a seemingly-simple framework to analyze the feminist and pharmaceutical cases. Taking the feminist case first, we can analyze the epistemic contributions of feminists scientists into two kinds. First, as per Wylie's analysis, feminist scientists identified various androcentric assumptions in accounts of the development of agriculture, and so showed that these values had influenced the acceptance of these accounts. Insofar as these androcentric values did not compete with or override considerations of evidence, this is compatible with the lexical priority of evidence. But it also means that the evidence by itself is insufficient to determine or rationally compel the acceptance of these accounts. Therefore, feminist scientists may legitimately reject these accounts simply for the reason that they depend on androcentric values, and in addition feminist scientists may legitimately develop rival accounts that use feminist values in similar ways, so long as these values do not override considerations of evidence.

Next, as Schiebinger pointed out, women and men in archaeology typically worked with different sets of stone tools. Weapons, studied by men, were used to support the man-the-hunter hypothesis; feminist scientists emphasized stone tools and other artifacts used for things like food preparation in the village, and thereby expanded the range of 
evidence against which the man-the-hunter hypothesis had to be evaluated. With this expanded evidence base, feminist scientists argued that the hypothesis was empirically inadequate. This is the second kind of epistemic contribution. With both kinds, the influence of feminist values did not override considerations of evidence; so they are consistent with the lexical priority of evidence; and thus according to this analysis both kinds of influence are legitimate.

Turn now to the pharmaceutical case. It is initially plausible to say that commercial values ran roughshod over considerations of evidence, and so the influence of commercial values here was illegitimate. However, consider more carefully the email exchange between Merck scientists about how to classify the death of a patient, as reported by Berenson. The autopsy listed the cause of death as Hypertensive Heart Disease, and because the study was double-blind the Merck scientists did not know whether she was taking Vioxx or the control. One of the scientists reasons that "[c]ommon things being common," the likely cause of death is a heart attack, but "[c]ertainly, it is not definitive" and "[i]f it is easier to call this an unknown cause of death, I could be persuaded to say that as well." The other scientist responds that "the committee would not have said this was [a heart attack] and I think this is the best way to go since it leaves the process in place" (Berenson 2005). Due to the lack of context, it's not clear exactly which committee is meant; Berenson suggests but does not state outright that it is an outside committee of academic researchers, responsible for reviewing case reports in such trials. Berenson reports that this particular case was not sent to this committee.

All together, it seems that the classification of the cause of death in this patient's case was underdetermined by the available evidence, that is, the autopsy report: perhaps it was a heart attack, but perhaps not. Therefore it is plausible to say that the Merck scientists took the available evidence as far as it could go - they didn't try to classify it as kidney failure, for example - and subsequently but only subsequently were commercial values used to classify the cause of death as unknown. Hence, it is plausible to judge that commercial values did not override considerations of evidence, and therefore were consistent with the lexical priority of evidence, and so were legitimate. 
On this analysis, we have two plausible readings of the pharmaceutical case, one concluding that the influence was illegitimate and the other concluding that it was legitimate. The situation is even more difficult with other cases, for which we do not have the fine-grained documentary evidence that Berenson has provided. As McHenry and Jureidini put it, "What is not clear from the available documents is who was responsible for the manipulation of the data. This is the risk of using a ghostwriter to prepare a manuscript” (McHenry and Jureidini 2008, 156).

Even if we grant that commercial values ran roughshod over considerations of evidence in the pharmaceutical case, the appeal to the lexical priority of evidence is problematic. To make this argument, I would like to shift the language slightly, from evidence to truth. ${ }^{8}$ The lexical priority of evidence over (ethical and political) values, it seems, assumes that one takes truth to be more important than the ethical and political values in question. That is, only insofar as truth as a value takes priority over all other values. Certainly truth is valuable; but why is it so valuable that it enjoys absolute, lexical priority over all other values?

Among academics, including scientists and philosophers, truth as a value might be generally regarded as having lexical priority over other values (compare Douglas 2009, 95; Talisse 2010). But pharmaceutical industry representatives might take truth to be only instrumentally valuable, that is, valuable only for the sake of other valuable things. And they might not take truth to be intrinsically valuable, that is, valuable for its own sake. For instance, they might think that true beliefs concerning the effects of a drug are valuable only for the sake of making lots of money. Indeed, insofar as true beliefs concerning these effects prevent making lots of money - because no one will use the drug if they know that it's dangerous and not very effective - the pharmaceutical industry representatives might think that truth is $b a d$, not good, and so truth should be sacrificed for the sake of making lots of money. In short, they might take their profits to enjoy priority over truth!

\footnotetext{
8. Recall from note 1 that I am not assuming any specific conception of truth, or even whether "truth" is a more appropriate term than, say, "empirical adequacy"; and by "truth as a value" I mean truth regarded as good and worth having (by us), whatever truth is as such.
} 
Consequently, the initial analysis of the pharmaceutical case - the pharmaceutical case is illegitimate because truth should take priority to commercial values - has no traction with these pharmaceutical industry representatives. They simply don't accept the major premise. I grant that this argument is persuasive to many academics. But, without an argument for the lexical priority of truth, it will not be persuasive to many other people.

One might try to argue that truth is valuable from an arbitrary perspective insofar as truth is useful for achieving whatever aims that perspective might have. (This is one way of reading Talisse's views.) If you want gender equality, it helps to believe true things about sex and gender; if you want to make a lot of money by selling drugs, it helps to believe true things about what your drugs do. But, again, this is only to say that truth has instrumental value. Thus, again, when there is a conflict between truth and the aim in question - say, pharmaceutical industry profits - there is a pro tanto reason to sacrifice truth.

Alternatively, one might argue that the internal perspective of science (and academia more generally) is all the more scientists (and philosophers and other academics) should care about. $^{9}$ We might say that the pharmaceutical industry representatives are profoundly misguided in their low evaluation of truth; or, alternatively, that pharmaceutical industry representatives have a right to decide for themselves how (un)important truth is for them. In either case, scientists should simply get on with their research - should pursue truth - rather than waste time in interminable debate over the importance of various values.

Except that, in its current institutional context, the pharmaceutical industry representatives have enormous power over the pharmaceutical research that is actually carried out. The ability of pharmaceutical researchers to simply get on with their research depends on the support of the pharmaceutical industry representatives, and thus on the expected profitability of this research. Pharmaceutical researchers cannot, as it were, remain within the internal perspective of science; they must justify their research from the external perspective of the pharmaceutical industry.

9. I thank Charles Pence for pressing this point. 


\section{Epistemic and non-epistemic values}

A second tool for trying to distinguish the influence of values in our two cases is the distinction between epistemic and non-epistemic values. The distinction was developed in the late 1970 s and early 1980 s as a response to Kuhn's underdetermination arguments in The Structure of Scientific Revolutions, including by Kuhn himself (Kuhn 1977; McMullin 1983). Proponents of the distinction granted proponents of underdetermination that there was a gap between evidence and hypothesis; but, they said, this gap should be filled by such epistemic or "truth-promoting" values as explanatory power and simplicity, rather than "non-epistemic" ethical and political values. Thus, while the letter of the value-free ideal should be rejected, the spirit remained intact. In response, some feminist philosophers of science argued that the distinction between epistemic and nonepistemic values was not as sharp as it seemed, and that ethical and political values may legitimately lead us to prefer some epistemic values to others (Rooney 1992; Longino 1995, 1996).

In some recent papers, Daniel Steel has further developed the epistemic/non-epistemic distinction. Steel defines epistemic values as those that "promote the attainment of truth" or "the acquisition of true beliefs" (Steel 2010, 17-8). Steel notes that whether something is epistemic can be context dependent:

Internal consistency is a straightforwardly ... epistemic value, since it is a necessary condition for truth. Whether external consistency is an epistemic value, however, depends on the truthfulness of the accepted background beliefs. If those beliefs are significantly false (e.g., that the earth is the center of the universe and is no more than 10,000 years old), then external consistency can be a major impediment to the attainment of truth. $(18$, his parentheses)

To distinguish legitimate from illegitimate cases, Steel proposes what I will call his influence principle: "Influences of nonepistemic values on scientific inferences are epistemically bad if and only if they impede or obstruct the attainment of truths" (15, my emphasis; see also 25ff). In a subsequent paper with Kyle Powys Whyte, the principle is weakened 
slightly - to deal with such problems as unethical research designs - but retains the basic idea: "nonepistemic values should not conflict with epistemic values in the design, interpretation, or dissemination of scientific research that is practically feasible and ethically permissible" (Steel and Whyte 2012, 169).

Steel's contextual understanding of epistemic values accommodates insights from all of the thinkers cited in the first paragraph of this section. On the one hand, epistemic values have a special role or function in accepting hypotheses, and the legitimate role of non-epistemic values is limited by their relation to epistemic values. On the other hand, consider a specific element of Longino's argument against the epistemic/non-epistemic distinction. She contrasts the traditional or mainstream value of simplicity with a feminist value of "ontological heterogeneity," which values complexity (1995, 392; 1996, 46-7). While simplicity leads to taxonomies with only a few different categories — such as aggressive, domineering, promiscuous males and passive, submissive, coy females ontological heterogeneity leads taxonomies with a variety of different kinds of beings in the world and variation among individuals — such as the wide variety of female and male reproductive strategies. Steel's account of epistemic values supports an argument that simplicity and ontological heterogeneity are complementary epistemic values. Simplicity will probably lead us to true broad generalizations, but also will probably lead us to overgeneralize and miss exceptions; whereas ontological heterogeneity will probably lead us to true claims about very specific groups, but also miss generalizations that do indeed apply generally and for the most part. Thus, in contexts in which one value has been promoted and the other has been neglected, we will tend to get certain kinds of truths but miss others. The complementary value will then serve as a corrective, as it were returning us to the virtuous mean between the vicious extremes. Recognizing this, within the broader scientific community different groups of scientists may legitimately (indeed, should) pursue research programs that emphasize one epistemic value over the other, motivated (in part) by their respective ethical and political values, so long as interactions between the groups ensure that the scientific community as a whole tends towards truth. Stated less abstractly: in the feminist case, the influence of feminist scientists, and so the influence of feminist values, corrected an overemphasis on simplicity, thereby promoting the attainment of truths; hence it was epistemically good. Indeed, in 
this context, insofar as feminist values promoted the attainment of truth, they were both epistemic and social-political values.

Obviously the analysis in the preceding paragraph can serve as a paradigm for analyzing the feminist case: an overemphasis on simplicity, reductionism, and so on, was impeding and obstructing the attainment of truths; feminist criticism led us away from the vicious extreme and back to the virtuous, truth-promoting mean. So the influence of feminist values was legitimate. This fits well with my preliminary sketch assessment of this case.

Steel and Whyte provide a second paradigm in their analysis a study of environmental racism, a hypothesized connection between race and exposure to harmful pollution. Their analysis begins by noting that Deborah Mayo's severity principle - developed from Popper - is an important epistemic value: "data $x_{o}$ do not provide good evidence for hypothesis $H$ if $x_{0}$ result from a test procedure with a very low probability or capacity of having uncovered the falsity of $H$ (even if $H$ is incorrect)" (Mayo and Spanos, quoted in Steel and Whyte 2012, 168). They next argue that the particular environmental racism study that they are analyzing indeed had a low capacity for uncovering the falsity of the hypothesis that there is a strong correlation between race and pollution exposure, assuming that it is actually false (177). Finally, since this study was funded by Waste Management Inc., they conclude that non-epistemic commercial values could have led to these conflicts with the epistemic value articulated by the severity principle. That is, in this case there could have been a violation of the influence principle.

This second paradigm seems appropriate to the pharmaceutical case. Indeed, we can even use the severity principle again. Recall that one of the main ways in which commercial values had an influence in the pharmaceutical case was through the interpretation of ambiguous data. Doing this decreases the capacity of the studies to uncover the falsity of the hypotheses that the drugs in question are safe and effective, assuming that these hypotheses are actually false. Thus, as in the environmental racism case, commercial values seem to have overridden the epistemic value articulated by the severity principle. And so it seems there was a violation of the influence principle in the 
pharmaceutical case. As with the feminist case, this analysis seems to fit well with my preliminary sketch assessment of the pharmaceutical case.

However, note that Steel's influence principle only identifies cases where the influence is epistemically bad. This only implies that the influence is bad simpliciter insofar as we assume something like the lexical priority of truth. Or, to be a bit more precise, Steel must assume that the pursuit of truth enjoys lexical priority over such values as pharmaceutical industry profits. But then the argument that I used against the lexical priority of truth in the last section also applies here: Suppose the pharmaceutical industry representatives maintain that truth is less important than their profit margins. Indeed, suppose they maintain that truth is valuable only insofar as truth promotes the attainment of profit. Then, when truth impedes or obstructs the attainment of profit, truth should be sacrificed. For all that the interpretation of data in the pharmaceutical case was epistemically bad, it was profitable, and from this perspective profitability outweighs epistemic badness. Thus the actions of pharmaceutical industry scientists were, from their perspective, entirely legitimate.

There is another, related problem. Steel and Whyte argue that their approach does better than Heather Douglas' direct/indirect role distinction - discussed in the next section - in part because their approach recognizes distinctions between different kinds of values, Douglas treats all values the same way (163-4). But Steel and Whyte distinguish between only epistemic and non-epistemic values. Suppose that the pharmaceutical industry scientists argued that their actions were justified not for the sake of profits but instead of the sake of promoting the health of patients (compare 171): interpreting a small number of ambiguous cases in the way that they did enabled them to bring to market sooner drugs that could be immensely beneficial to large numbers of people. In this version of the pharmaceutical case, the conflict is between epistemic values and the non-epistemic value of patient health; the violation of the influence principle is otherwise exactly the same as in the original version of the case. Yet I suspect that many people who think balancing epistemic values against profitability is easy - profits should be sacrificed - would find it much more difficult to balance epistemic values against patient health, and might even say that it is good all things considered to do so 
in some cases. That is, minimally, for the purpose of deciding whether the sacrifice of some epistemic values was good or bad all things considered, it is plausible to think that there are relevant differences between the non-epistemic values of profit and patient health. Thus, because it is not sensitive to differences among kinds of non-epistemic values, the influence principle returns the judgment that a sacrifice of epistemic values was epistemically bad even in cases in which it was plausibly good all things considered. Finally, since the practical question is always "what shall we do, all things considered?" it is at least unclear whether the influence principle can provide practical advice, as Steel and Whyte think that it can (for example, at Steel and Whyte 2012, 167, 177).

As with the appeal to the lexical priority of evidence, the distinction between epistemic and non-epistemic values does not give us an adequate way to determine which values are more important than others. We might, as Steel does, posit that epistemic values are more important. But this at best begs the question against those who take other values to be more important and it limits the ability of our philosophy of science to provide practical advice.

\section{Direct and indirect roles}

In recent work, Heather Douglas has developed a distinction between direct and indirect roles for values. "Values," as Douglas uses the term, include ethical and political values as well as such traditionally epistemic values as simplicity and explanatory power (Douglas 2009, 89, 92ff). In the epistemic phase, if values were to play the direct role then they would "act as reasons in themselves to accept a claim" and so "act much the same way as evidence normally does"; in an indirect role, which "values ... determine the importance of the inductive gaps left by the evidence" (96) or set standards for evidence - how much of what kinds of evidence is required to accept or reject a hypothesis. On Douglas' view, values may not legitimately play the direct role, and may have a legitimate influence only in the indirect role (though they may legitimately play a direct role in the pre- and post-epistemic phases; see $98 \mathrm{ff}$ ).

In the next few paragraphs, I offer two readings of each of the pharmaceutical and feminist cases. On the first readings, Douglas' account matches our intuitions in $\S 2$ : 
values are playing an illegitimate direct role in the pharmaceutical case, and a legitimate indirect role in the feminist case. On the second readings, Douglas' account seems to reach exactly the opposite conclusions. My claim is not that Douglas' account is committed to one set of readings or the other. Rather, my point is that the analysis of the two cases, using the distinction between direct and indirect roles and the evidence available to us (about individuals' intentions and so on), is ambiguous or inconclusive. Note that I gave a similar argument against the lexical priority of truth in $\S 3$.

One very plausible reading of the pharmaceutical case is that commercial values are playing an illegitimate direct role in the epistemic phase: that they are leading to evidence being suppressed, ignored, or distorted. I grant that this reading is quite plausible. But we might also read the pharmaceutical case as one in which commercial values legitimately are leading to extreme standards of evidence - very, very low standards for efficacy claims and very, very high standards for hazard claims. In the eyes of pharmaceutical industry representatives, perhaps getting these pharmaceuticals to market as fast as possible and selling them to as many people as possible is much, much more important than the risk of making errors about side effects or effectiveness. At least from their perspective, the risk of reduced profits - or having to scrap the drug entirely, wasting millions of dollars and dozens of researcher-years - outweighed other risks, and so they established a low standard of evidence for claims about side effects and effectiveness and interpreted ambiguous cases in favorable ways. Recall from the Vioxx case again that the heart attack victim case was classified as an "unknown cause of death" because that "leaves the process in place" and "[doesn't] raise concerns" (Berenson 2005; compare Douglas 2000, §5, 569-72). The scientists would have classified this case as a heart attack, but only if the evidence had been much more substantial or unambiguous than it actually was. On this reading, the evidence was uncertain about how these cases should be classified, and commercial values played only an indirect role. They would therefore seem to be legitimate. (For a somewhat similar example, see Steel and Whyte 2012, especially 170-3.)

As for the feminist case, one plausible reading is that feminist values played an entirely legitimate indirect role, in that feminists' suspicions of androcentrism and other 
forms of bias led them to demand much more and better evidence for androcentric theories. But it is also plausible to think that feminist values played an illegitimate direct role, in that feminists rejected andorcentric theories simply because these theories were androcentric.

Consider the following sketch of a narrative of feminist archaeology: Prior to the $1980 \mathrm{~s}$, the almost-all-male researchers in archaeology had an accepted set of methods, explanatory frameworks, broad theories, specific hypotheses, and so on. Many of these theories were androcentric. As a generation of women entered the field, many of them had feminist commitments; these commitments led them to be suspicious about these sexist and androcentric accepted theories. Their research eventually produced robust and influential criticisms, undermining evidence, alternative theories, and so on. Often the old methods were inconsistent with other methods, the old explanatory frameworks were empirically inadequate, and the most sexist and androcentric background assumptions were undermined by the tides of social change.

In this narrative sketch, the epistemic phase - the acceptance or rejection of theories - occurs at least three times:

(1) In the acceptance of the earlier/sexist or androcentric theories by prior generations of researchers.

(2) In the rejection of these theories by the generation of feminist researchers.

(3) In the widespread acceptance of the new, non- or less-sexist or -androcentric theories by the peers of the feminist researchers or the following generations of researchers.

It may be possible to read the first and third times as values legitimately setting standards of evidence: sexist values set low standards of evidence for sexist or androcentric theories; later, feminist values placed higher standards of evidence for sexist or androcentric theories, and lower standards for more egalitarian theories. However, the second time occurred before there was much systematic evidence to undermine the accepted theories. This is not to say that there was no such evidence; feminist scientists pointed 
to undermining evidence in making their case that the accepted theories should be rejected. But, by and large, the rejection of the accepted theories was based primarily on feminist values. Only subsequently, after rejecting the accepted theories, did feminist scientists systematically accumulate the significant evidence that eventually undermined the earlier theories in the eyes of the broader scientific community. As Wylie puts it, two feminist archaeologists "commissioned a series of pilot projects on gender that they hoped might demonstrate the potential of research along the lines proposed by Conkey and Spector 1984" (Wylie 2002, 189, my emphasis). Thus, by Douglas' lights, it would seem that the earlier influence of sexist values was indirect, and thus legitimate; but, at least initially, the influence of feminist values was direct, and thus illegitimate.

All together, Douglas' account seems to be ambiguous: we may read the influence of values in either case as legitimate or illegitimate.

It may be objected that I have not produced the kind of empirical, historical support that the problematic readings require. How do I know that feminists archaeologists rejected the androcentric theories merely because they were androcentric? How do I know that pharmaceutical industry scientists carefully limited the role of commercial values to setting standards of evidence?

But these questions actually support my point. I don't know these things. And neither does the objector, or indeed anyone else. At best, Douglas' account seems to indicate that we should reserve judgment about whether these cases were legitimate or illegitimate until we have much, much more evidence. We must carefully sort out the different phases of the research process and examine the researchers' intentions and reasoning. Who made which decisions about classifying the death of the Vioxx patient? Who decided how to interpret the Paxil trial data? What role did evidence play in their deliberations? In exactly what ways did commercial values come into play? And so on. Yet the pharmaceutical case seems to me to be clearly and egregiously illegitimate. I suggest that gathering additional evidence will not change our basic evaluation of these cases (e.g., that something has gone very wrong in the pharmaceutical case), though they 
might change our understanding of important details or our assessment of responsibility. ${ }^{10}$ Indeed, gathering some of these pieces of evidence will simply be impossible. Does this mean that we must reserve judgment forever? Not only is that impractical, it also conflicts with the ease with which we made judgments about these cases in $\S 2$.

Alternatively, it may be objected that the rejection of the accepted methods in the feminist case was part of a pre-epistemic, not epistemic, phase. That is, one might argue that the feminist scientists were choosing a research program (to challenge the doxastic status quo), not taking an epistemic attitude (rejection or non-acceptance) or challenging the standards for acceptance and rejection. Since choosing a research program is part of the pre-epistemic phase, and the direct role for values is legitimate in the pre-epistemic phase, the influence of feminist values here was entirely legitimate.

However, it seems to me that these three possibilities — "choosing this research program," "taking the epistemic attitude of rejection," and "challenging the epistemic standards" - are three descriptions of one and the same activity (for a similar point, see Elliott and McKaughan 2009). Insofar as the feminist scientists were choosing a research program that challenged the status quo, they were rejecting the claims that constituted that status quo, judging them to be inadequately supported or even undermined by the evidence; and insofar as they were judging the claims to be inadequately supported by the evidence, they were challenging the standards of what counted as good, support-lending evidence. It may be useful for philosophy of science to make conceptual distinctions among pre-, post-, and epistemic phases of scientific for certain analytic purposes, such as mathematical treatments of the relationship between evidence and hypothesis. That is, these taxonomies may be useful as Galilean idealizations of science itself (McMullin 1985). But these phases are often entangled, inseparable, or even conceptually indistinguishable in actual scientific practice. As the feminist case shows, what seems to be the epistemic phase under one description can be the pre-epistemic phase under another, equally good description.

10. The Knobe Effect suggests that the value we assign to the consequences of the Paxil trial will influence our assessment of the role of commercial values in the researchers' intentions and reasoning, and so our assessment of the case according to Douglas' account. Specifically, the effect predicts that we, insofar as we take these consequences to be bad, we will probably say that the researchers intended to bring them about (Knobe 2003). And it is reasonable to interpret this as an illegitimate direct role for values in the epistemic phase. I thank an anonymous reviewer for this point. 
The distinction among pre-, post-, and epistemic phases is like a frictionless plane: useful for some analytic purposes, but often not straightforwardly applicable to the concrete complexities of the real world. Specifically, in the pharmaceutical and especially the feminist cases, it seems to be a source of more confusion than clarification. But Douglas' account of legitimate and illegitimate influences of values depends entirely on this distinction: direct influences are legitimate pre- and post-, but not in the epistemic phase. Thus, like the other two approaches, Douglas' approach does not support an adequate account of the two cases.

\section{Conclusion: A New Direction}

In the preceding sections, I have examined three major conceptual tools developed in the science and values literature for distinguishing legitimate and illegitimate influences of ethical and political values. I have argued that that none is adequate to this task. In this final section, I will begin to develop the sketch given at the end of $\S 2$ using my own approach. This approach draws heavily on work in ethics, especially by Aristotle (1984), John Dewey (1988), Philippa Foot (1972), Alasdair MacIntyre (1984, ch. 14), Henry Richardson (1994), and Elizabeth Anderson (2005/2008). I will suggest that it avoids the problems faced by the other approaches, including analytical ambiguities, failing to distinguish different kinds of non-epistemic values, and the lexical priority of truth.

Recall from the end of $\S 2$ the observation that, at least in the particular cases at hand, the influence of commercial values frustrated the epistemic aims of science in a word, truth - while the influence of feminist values promoted these aims. Put more generally, from the scientific perspective, in the pharmaceutical case constitutive values of science and contextual values from the pharmaceutical industry are mutually antagonistic, while in the feminist case the constitutive and contextual values are mutually synergistic. ${ }^{11}$ Hence, from this perspective, the influence of commercial values in the pharmaceutical case was illegitimate, while the influence of feminist values in the feminist case was legitimate.

\footnotetext{
11. The terminology of constitutive and contextual values is due to Longino (1990, 4ff), and these concepts have not enjoyed much further development in recent years. An anonymous reviewer suggests that Kitcher's account of broad, cognitive, and probative values is a development of Longino's concepts (Kitcher 2011, 37-9; see also Brown 2013a).
} 
Thus far, the approach sounds very much like Steel's use of the epistemic/nonepistemic distinction. However, there are two important differences. First, on my approach the constitutive values of science include but are not limited to "purely epistemic" values, such truth (narrowly construed) or empirical adequacy. Other constitutive values of science include practical knowledge, or know-how, and the development of socially useful technology (Baird 2004; Cartwright 2006; Tuana 2012; Brown 2012; Douglas, forthcoming; and arguably also Kitcher 2011). Likewise, on my approach, a "purely epistemic" attitude of acceptance is not more important than a pragmatic attitude of endorsement. This first feature makes it possible for my approach to recognize some synergies that Steel's does not. For example, in some cases commercial values might promote the development of socially useful pharmaceuticals; since the latter is one of the constitutive values of biomedical scientific research, in these cases the constitutive and contextual values are mutually synergistic. ${ }^{12}$

The other important difference with the epistemic/non-epistemic distinction relates to the qualification "from the scientific perspective" the lexical priority of truth. My criticisms of this priority can be understood as recognizing that other groups of people, such as the pharmaceutical industry, have their own constitutive values, and from their perspectives the various values of scientific research are contextual. Specifically, truth is of paramount importance from the scientific perspective, yet it is much less important than the constitutive value of profit from the pharmaceutical industry perspective.

Despite being tied to particular perspectives, these claims still have evaluative force, at least (though perhaps not only) for the individuals who inhabit those perspectives. Specifically, evaluative claims based on the constitutive values of the scientific perspective have evaluative force for scientists, while evaluative claims based on the constitutive values of the pharmaceutical industry have evaluative force for individuals within this

12. Up to this point in the paper, I have generally used "values" because it is the term used in the literature that I am discussing, viz., the "science and values" literature. However, my approach is better put in the language of various goods, which are the aims or ends or goals of various activities or social practices. Some of these goods are the constitutive aims of these activities; for example, truth and useful technology are two goods that are among the constitutive aims of the activity of scientific inquiry. For the sake of continuity with the rest of this paper, in the text I will stick with "values," though occasionally this makes for some awkward phrasing. Compare the language of this note with Longino 1990, 17-9. 
industry. In this way, evaluation and normativity start from the commitments and interactions of some particular people engaged in some particular collaborative activities, rather than from universally-binding fundamental principles (MacIntyre 1984, ch. 14; Rouse 2007). This may be thought problematic; unfortunately, I do not have sufficient space here to take up that problem. For an argument that this kind of approach need not collapse into a pernicious relativism, see MacIntyre (2006).

My analysis of the feminist case is straightforward. The interaction with science in this case helped promote feminist values — something like undermining androcentric ideology - and so was legitimate. Note that this judgment is particular to the case: in cases in which science is antagonistic to or frustrates the pursuit of feminist values, feminists will be at least much more skeptical about interacting with science. (For example, the relationship between feminism and evolutionary psychology is much more fraught; see Fehr 2012.) In addition, we do not need to carefully inspect feminist scientists' intentions or subjective reasoning processes to identify the synergy (or antagonism) between scientific and feminist constitutive values. In the 1980s it may have been controversial whether feminist values were synergistic or antagonistic to scientific values. For example, isolationist archaeologists may have worried that feminists were illegitimately trying to impose a partisan political agenda or "political correctness" on archaeology. But, in line with the analyses of the feminist case in $\S \S 3$ and 4 , feminist scientists could claim that their approach had the potential to be more empirically adequate, broaden the set of available evidence, correct an overemphasis on simplicity, and in general promote the constitutive values of scientific inquiry. Therefore their work should be given a chance to realize this potential, and in retrospect we can say that it did. Thus, the analysis of the feminist case is not ambiguous.

The pharmaceutical case is more complicated. On my approach, rather than starting with the constitutive values of science - assuming the lexical priority of truth we should start with the constitutive values of the pharmaceutical industry. It seems that profit is one such value. But another such value is the health and well-being of the industry's consumers/patients. We thus have at least three values in play: profit, 
patient health, and contextual values (from the industry's perspective) coming from science. While industry representatives might attempt to claim that the interactions among these three are synergistic, it seems clear that, at least in the particular cases I presented in $\S 2$, the pursuit of profit is antagonistic to both patient health and scientific values.

It therefore seems to be necessary to sacrifice certain of these values for the sake of others. I would argue first that profit is strictly instrumentally valuable - valuable only for the sake of spending it on other things, not for own sake - while health is both instrumentally and intrinsically valuable. Indeed, on the plausible assumption that constitutive values must be intrinsically valuable, it follows that profit is not actually a constitutive value of health care. Instead, it is merely part of the institutional apparatus by which we provision health care. In other words, the profit motive is merely the way in which our market system gets people (or tries to get people) to provide health care, develop new pharmaceuticals, and so on, all for the sake of promoting health. Profit is merely a means and health is the intrinsically valuable, constitutive end.

But this last point implies from the perspective of the pharmaceutical industry that it is wrong to sacrifice patient health for the sake of profit, as happened in the pharmaceutical case. By contrast, while scientific values are contextual and thus perhaps strictly instrumentally valuable (again, from the perspective of the pharmaceutical industry), promoting them would have been a more effective way to promote the constitutive value of patient health. So we can conclude that from the perspective of the pharmaceutical industry it was wrong to sacrifice scientific values for the sake of profit in the pharmaceutical case. As with the feminist case, this analysis does not depend on in-principle unavailable evidence about the intentions or subjective reasoning processes of industry scientists. Nor does it depend on how we describe their actions.

Note three features of this approach. First, it recognizes on the lexical priority of truth and the epistemic/non-epistemic distinction, insofar as scientists accept them, but in ways that avoid the problems I identified with them above. Second, it uses an ethical framework rather than an epistemological one, and specifically ideas about practical reasoning in contexts where there are specific values or goals. Thus, by design and in contrast with some points I made about Steel's approach, my approach supports 
distinctions among various kinds of non-epistemic values and is immediately relevant to the practical question "what shall we do, all things considered?"

Third, my approach brings together both epistemological and ethical issues. Philosophers of science have done excellent work on the epistemological aspects of values in science. And some ethicists have begun to examine the ethical issues raised by commercialized science (Resnik 2010). But the problem of distinguishing legitimate and illegitimate influences of ethical values in science is both ethical and epistemological, and indeed I think we must consider interactions between the ethical and epistemological aspects of the problem. This requires juxtaposing these issues in ways that cannot be done within one philosophical specialization or the other.

The presentation of my approach here must be limited to the bits and pieces that I have offered in this section. But I do believe I have given good reason to expect it to be more promising than the other approaches that I have examined.

\section{References}

Amsterdam, Jay, and Leemon McHenry. 2012. "The Paroxetine 352 Bipolar Trial: A Study in Medical Ghostwriting." International Journal of Risk and Safety in Medicine 24:221-31. doi:10 .3233/JRS-2012-0571.

Anderson, Elizabeth. 2004. "Uses of Value Judgments in Science." Hypatia 19 (Winter): $1-24$.

2005/2008. "Dewey's Moral Philosophy." In The Stanford Encyclopedia of Philosophy, edited by Edward N. Zalta. http://plato. stanford.edu/archives / fall2008/entries/dewey-moral/.

Aristotle. 1984. Nicomachean Ethics. In The Complete Works of Aristotle, edited by Johnathan Barnes, 1729-1867. Princeton: Princeton University Press.

Baird, Davis. 2004. Thing Knowledge: A Philosophy of Scientific Instruments. Berkeley and Los Angeles: University of California Press.

Barnes, Barry, and David Bloor. 1982. "Relativism, Rationalism and the Sociology of Knowledge." In Rationality and Relativism, edited by Martin Hollis and Steven Lukes, 21-47. Cambridge, MA: MIT Press.

Berenson, Alex. 2005. "Evidence in Vioxx Suits Shows Intervention by Merck Officials." New York Times (April 24).

Betz, Gregor. 2013. "In Defence of the Value Free Ideal." European Journal of Philosophy of Science 3, no. 2 (May): 207-20. doi:10.1007/s13194-012-0062-x. 
Biddle, Justin. 2007. "Lessons from the Vioxx Debacle: What the Privatization of Science Can Teach Us about Social Epistemology.” Social Epistemology 21 (1): 21-39.

2009. "Advocates or Unencumbered Selves? On the Role of Mill's Political Liberalism in Longino's Sociopragmatism.” Philosophy of Science 76, no. 5 (December): $612-623$.

Brown, Matthew. 2011. "Inquiry and Evidence: From the Experimenter's Regress to Evidence-Based Policy." Unpublished manuscript. Accessed August 20, 2012. http: / / utdallas . academia . edu / MatthewBrown / Papers / 300331 / Inquiry_and_ Evidence_From_the_Experimenters_Regress_to_Evidence-Based_Policy.

. 2012. "John Dewey's Logic of Science." HOPOS: The Journal of the International Society for the History of Philosophy of Science 2, no. 2 (Fall).

- 2013a. "Review of Philip Kitcher, Science in a Democratic Society." Notre Dame Philosophical Reviews. March 7. Accessed March 12, 2014. http://ndpr.nd.edu/ news/29284-science-in-a-democratic-society/.

- 2013b. "The Source and Status of Values for Socially Responsible Science." Philosophical Studies 163, no. 1 (March): 67-76.

. 2013c. "Values in Science beyond Underdetermination and Inductive Risk." Philosophy of Science 80, no. 5 (December): 829-39.

Callaway, Ewen. 2010. "Questions over Ghostwriting in Drug Industry." Nature News Blog. September 7. Accessed August 22, 2011. doi:10 .1038/news . 2010 . 453. http: //www.nature.com/news/2010/100907/full/news.2010.453.html.

Cartwright, Nancy. 2006. "Well-Ordered Science: Evidence for Use.” Philosophy of Science 73.

Dewey, John. 1988. Theory of Valuation. In John Dewey: The Later Works, 1925-1953, edited by Jo Ann Boydston, 13: 1938-1939:189-251. Carbondale and Edwardsville: Southern Illinois University Press.

Douglas, Heather. 2000. "Inductive Risk and Values in Science.” Philosophy of Science 67 (4): 559-79.

. 2009. Science, Policy, and the Value-Free Ideal. Pittsburgh: University of Pittsburgh Press.

2013. "The Value of Cognitive Values." Philosophy of Science 80, no. 5 (December): $796-806$.

. Forthcoming. "Pure Science and the Problem of Progress." Studies in History and Philosophy of Science.

Elliott, Carl. 2004. "Pharma Goes to the Laundry: Public Relations and the Business of Medical Education." Hastings Center Report 34 (5): 18-23.

Elliott, Kevin. 2011. Is a Little Pollution Good for You?: Incorporating Societal Values in Environmental Research. Oxford and New York: Oxford University Press. 
- 2012. "Epistemic and Methodological Iteration in Scientific Research." Studies in History and Philosophy of Science 43 (January 20): 376-82. doi:10 .1016/ j . shpsa. 2011.12 .034$.

Elliott, Kevin, and Daniel McKaughan. 2009. "How Values in Scientific Discovery and Pursuit Alter Theory Appraisal.” Philosophy of Science 76, no. 5 (December): 598-611. doi:10.1086/605807.

Fehr, Carla. 2012. "Feminist Engagement with Evolutionary Psychology." Hypatia 27, no. 1 (Winter): 1-23.

Feyerabend, Paul. 1993. Against Method. Third edition. London and New York: Verso.

Foot, Philippa. 1972. "Morality as a System of Hypothetical Imperatives." Philosophical Review 81 (3): 305-16.

Friedman, Michael. 2001. Dynamics of Reason. Stanford: Center for the Study of Language / Information.

Fugh-Berman, Adriane. 2010. "The Haunting of Medical Journals: How Ghostwriting Sold 'HRT'.” PLoS Medicine 7, no. 9 (September): e1000335. doi:10 .1371/ journal . pmed. 1000335.

Hicks, Daniel. 2012. "Scientific Practices and their Social Context." PhD diss., University of Notre Dame.

Julious, Steven. 2013. "Efficacy and Suicidal Risk for Antidepressants in Paediatric and Adolescent Patients.” Statistical Methods in Medical Research 22, no. 2 (April): 190218. doi:10.1177/0962280211432210.

Jureidini, Jon, Leemon McHenry, and Peter Mansfield. 2008. "Clinical Trials and Drug Promotion: Selective Reporting of Study 329." International Journal of Risk and Safety in Medicine 20:73-81. doi:10.3233/JRS-2008-0426.

Kindcaid, Harold, John Dupré, and Alison Wylie, eds. 2007. Value-Free Science? Oxford and New York: Oxford University Press.

Kitcher, Philip. 2001. Science, Truth, and Democracy. Oxford and New York: Oxford University Press.

- 2011. Science in a Democratic Society. Amherst, NY: Prometheus Books.

Knobe, Joshua. 2003. "Intentional Action and Side Effects in Ordinary Language." Analysis 63, no. 279 (December 17): 190-4. doi:10.1111/1467-8284.00419.

Kuhn, Thomas. 1977. “Objectivity, Value Judgment, and Theory Choice.” In The Essential Tension, 320-339. Chicago: University of Chicago Press.

Lacey, Hugh. 1999. Is Science Value Free?: Values and Scientific Understanding. Routledge. - 2005a. "On the Interplay of the Cognitive and the Social in Scientific Practices." Philosophy of Science 72, no. 5 (December): 977-88.

- 2005b. Values and Objectivity in Science: The Current Controversy about Transgenic Crops. Lanham, Maryland: Lexington Books. 
Lacey, Hugh. 2013. "Rehabilitating Neutrality." Philosophical Studies 163, no. 1 (March): 77-83. doi:10.1007/s11098-012-0074-6.

Lacey, Hugh, and Pablo R. Mariconda. 2012. "The Eagle and the Starlings: Galileo's Argument for the Autonomy of Science-How Pertinent is it Today?" Studies in the History and Philosophy of Science 43, no. 1 (March): 122-31. doi:10.1016/ j . shpsa. 2011.10 .012$.

Ledford, Heidi. 2013. "Virtual Reality." Nature 498 (June 6): 127-9.

Longino, Helen. 1990. Science as Social Knowledge. Princeton: Princeton University Press. 1995. "Gender, Politics, and the Theoretical Virtues." Synthese 104, no. 3 (September): 383-97.

. 1996. "Cognitive and Non-Cognitive Values in Science: Rethinking the Dichotomy." In Feminism, Science, and the Philosophy of Science, edited by Lynn Hankinson Nelson and Jack Nelson, 39-58. Dordrecht: Kluwer Academic Publishers.

MacIntyre, Alasdair. 1984. After Virtue. Second edition. Notre Dame: University of Notre Dame Press.

- 2006. "Moral Relativism, Truth, and Justification." In Selected Essays: The Task of Philosophy, 52-73. Cambridge: Cambridge University Press.

Magnus, P.D. 2013. "What Scientists Know is not a Function of What Scientists Know." Philosophy of Science 80, no. 5 (December): 840-9.

McHenry, Leemon. 2009. "Ghosts in the Machine: Comment on Sismondo." Social Studies of Science 39, no. 6 (December): 943-47.

McHenry, Leemon, and Jon Jureidini. 2008. "Industry-Sponsored Ghostwriting in Clinical Trial Reporting: A Case Study.” Accountability in Research: Policies and Quality Assurance 15:152-67. doi:10.1080/08989620802194384.

McKaughan, Daniel. 2007. "Toward a Richard Vocabulary for Epistemic Attitudes: Mapping the Cognitive Landscape.” PhD diss., University of Notre Dame.

McMullin, Ernan. 1983. "Values in Science." In PSA 1982: Proceedings of the 1982 Biennial Meeting of the Philosophy of Science Association, edited by Peter Asquith and Thomas Nickles, 2:3-28. Philosophy of Science Association.

- 1985. "Galilean Idealization." Studies in the History and Philosophy of Science 16 (3): 247-73.

Mirowski, Philip, and Robert Van Horn. 2005. "The Contract Research Organization and the Commercialization of Scientific Research.” Social Studies of Science 35 (4): 503-48. doi:10.1177/0306312705052103.

Okruhlik, Kathleen. 1994. "Gender and the Biological Sciences." Canadian Journal of Philosophy (Supplement) 20:21-42.

. 2004. "Logical Empiricism, Feminism, and Neurath's Auxiliary Motive." Hypatia 19 (1): 48-72. 
Psaty, Bruce, and Richard Kronmal. 2008. "Reporting Mortality Findings in Trials of Rofecoxib for Alzheimer Disease or Cognitive Impairment: A Case Study Based on Documents From Rofecoxib Litigation.” Journal of the American Medical Association 299, no. 15 (April 16): 1813-7. doi:10.1001/jama.299.15.1813.

Radder, Hans. 2010a. "Mertonian Values, Scientific Norms, and the Commodification of Academic Research.” In Radder 2010b, 231-58.

, ed. 2010b. The Commodification of Academic Research. Pittsburgh: University of Pittsburgh Press.

Resnik, David. 2010. "Financial Interests and the Norms of Academic Science." In Radder 2010b, 65-89.

Richardson, Henry. 1994. Practical Reasoning about Final Ends. Cambridge, UK and New York: Cambridge University Press.

Rooney, Phyllis. 1992. "On Values in Science: Is the Epistemic/Non-epistemic Distinction Useful." In PSA 1992: Proceedings of the 1992 Biennial Meeting of the Philosophy of Science Association, edited by David Hull, Micky Forbes, and Kathleen Okruhlik, 2:13-22. Philosophy of Science Association.

Rorty, Richard. 1991. "The Priority of Democracy to Philosophy." In Objectivity, Relativism, and Truth, 175-95. Cambridge, UK and New York: Cambridge University Press.

Ross, Joseph, Kevin Hill, David Egilman, and Harlan Krumholz. 2008. "Guest Authorship and Ghostwriting in Publications Related to Rofecoxib: A Case Study of Industry Documents From Rofecoxib Litigation.” Journal of the American Medical Association 299, no. 15 (April 16): 1800-12. doi:10.1001/ jama.299.15.1800.

Rouse, Joseph. 2007. "Social Practices and Normativity." Philosophy of the Social Sciences 37, no. 1 (March): 46-56. doi:10.1177/0048393106296542.

Sandel, Michael. 1998. Liberalism and the Limits of Justice. Second edition. Cambridge, UK and New York: Cambridge University Press.

Schiebinger, Londa. 1999. Has Feminism Changed Science? Cambridge, MA and London: Harvard University Press.

Sismondo, Sergio. 2009a. "Ghosts in the Machine: Publication Planning in the Medical Sciences.” Social Studies of Science 39, no. 2 (April): 171-98.

- 2009b. "Ghosts in the Machine: Reply to McHenry (2009)." Social Studies of Science 39, no. 6 (December): 949-52.

Steel, Daniel. 2010. "Epistemic Values and the Argument from Inductive Risk." Philosophy of Science 77 (January): 14-34.

Steel, Daniel, and Kyle Powys Whyte. 2012. "Environmental Justice, Values, and Scientific Expertise.” Kennedy Institute of Ethics Journal 22 (2): 163-82. 
Sung, S.C., S.R. Wisniewski, G.K. Balasubramani, S. Zisook, B. Kurian, D. Warden, M.H. Trivedi, and A.J. Rush. 2013. "Does Early-Onset Chronic or Recurrent Major Depression Impact Outcomes with Antidepressant Medications? A CO-MED Trial Report.” Psychological Medicine 43, no. 5 (May): 945-60. doi:10.1017/S0033291712001742.

Talisse, Robert. 2010. “An Epistemological Defense of Democracy.” Critical Review 22 (2-3): 281-91. doi:10.1080/08913811.2010.508636.

Tuana, Nancy. 2012. "Embedding Philosophers in the Practices Of Science: Bringing Humanities to the Sciences.” Synthese (September 18). doi:10.1007/s11229-0120171-2.

van den Belt, Henk. 2010. "Robert Merton, Intellectual Property, and Open Science." In Radder 2010b, 187-230.

Van Fraassen, Bas. 1980. The Scientific Image. Oxford and New York: Oxford University Press.

Wadman, Meredith. 2011. "Paxil Study under Fire." Nature 475, no. 153 (July 12). doi:10 . 1038/475153a.

Wylie, Alison. 2001. "Doing Social Science as a Feminist: The Engendering of Archeology." In Feminism in Twentieth-Century Science, Technology, and Medicine, edited by Angela Creager, Elizabeth Lunbeck, and Londa Schiebinger, 23-45. Women in Culture and Society. Chicago and London: University of Chicago Press.

- 2002. Thinking from Things: Essays in the Philosophy of Archaeology. Berkeley and Los Angeles: University of California Press.

Wylie, Alison, and Lynn Hankinson Nelson. 2007. "Coming to Terms with the Values of Science: Insights from Feminist Science Studies Scholarship.” In Kindcaid, Dupré, and Wylie 2007, 58-86.

Rotman Institute of Philosophy, University of Western Ontario, London, Ontario, N6C 4C3, Canada

E-mail address: hicks.daniel.j@gmail.com 